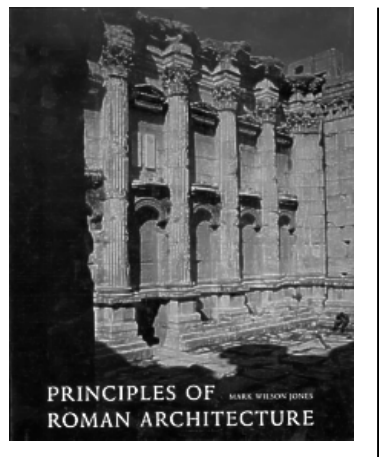

\title{
Mark Wilson Jones Principles of Roman Architecture
}

New Haven: Yale University Press, 2003

Reviewed by Sarah Clough Edwards

In his Principles of Roman Architecture, Mark Wilson Jones presents an intriguing and original examination of Roman construction, placing a strong emphasis on the mathematical and geometric systems employed by Roman architects. Key to the fresh insight presented in this volume is the decision of the author to formulate the majority of chapters not by building type, but by the investigation of themes within design practice. As Wilson Jones acknowledges in the preface, this structure allows for the most comprehensive study of shared principles across different building types. Traditionally, studies of Roman architecture have tended toward the archaeological, a problem addressed by the author. Recent works have broken with this tradition, in particular Rabun Taylor's Roman Builders: A Study in Architectural Process (Cambridge: Cambridge University Press, 2003) which adopts an approach similar to that of Wilson Jones in examining the realization of Roman buildings through their design process. The difference between the two texts lies in their focus. Taylor organizes his text to elucidate the mechanics of construction whilst Wilson Jones emphasizes the systems of proportion and geometry which he contends were employed by Roman architects.

The book is structured in two parts; Part One comprises seven chapters which effectively lead the reader through the process of designing and constructing a Roman building from first principles to the completed structure. Chapter One considers architecture as a profession in the Roman period and evaluates the architect's position in society. This opening chapter demonstrates how much can actually be understood about the architect as a professional figure, despite a paucity of knowledge regarding individual architects. No text on Roman architectural practice would be complete without a discussion of the best known Roman architect, Vitruvius, and Chapter Two serves this purpose. Wilson Jones provides a lucid précis of Vitruvian architectural theory, and his examination of the reception of Vitruvius by later scholars reaffirms the significance of the Roman architect.

Chapters Three, Four and Five examine the mathematics, geometry and proportional mechanisms that underpin classical architecture. Chapter Three considers building design and the formulation of ground plans. In examining a variety of building layouts Wilson Jones extrapolates from these examples the proportions which governed building projects, and demonstrates the dialogue between plan and elevation. Chapter Four continues by examining the place of number and measure in Roman construction. Chapter Five details a study of geometry and its importance in Roman construction in the creation of layouts and mosaic floor patterns. Particularly engrossing is the examination of Hadrianic geometry, whose use Wilson Jones perceives as both an intellectual and sensual technique, employed to create complex forms of great beauty. 
The final two chapters of Part One focus on column design, which Wilson Jones aptly calls 'the DNA of classical architecture'. Chapter Six considers column design in general, Wilson Jones's analysis addresses not only the appearance of finished columns but also the process of their creation. The examination of the geometric construction behind the fluting of columns illuminates the mathematics and geometry, behind even the minute details of a complete design. From the wide range of examples presented it is evident that hybridization of the orders and the mixing of types between capital and frieze was common. Wilson Jones singles out the Corinthian order, calling it 'the Roman order' and it is examined in particular detail in the final chapter of Part One. In focusing on a single feature of Roman construction, and one which is so widespread, Wilson Jones is amply able to demonstrate both that a governing set of principles were in place in the imperial Roman period, and that these principles were sufficiently flexible to allow great variety in Corinthian design.

Part One is encyclopaedic in the amount of information and data it presents to the reader. Additionally, the first seven chapters admirably demonstrate the geographical breadth of the Roman empire and its architecture, looking well beyond the buildings of the city of Rome to include examples from, amongst others, Israel, Libya, Tunisia and Algeria. However, the danger of such an approach, to an uninformed reader, is to imply links between visually similar structures, where in actuality there are none.

Part Two of the book is composed of three detailed case studies of architectural projects in the city of Rome. Chapter Eight considers the design of Trajan's Column, whilst Chapters Nine and Ten address the interior and exterior design of the Pantheon respectively. Whilst these chapters mark a divergence from the author's stated aim of examining general principles rather than typological studies, they are of obvious value in presenting the theory of Part One in distinct case studies. For readers whose mathematical understanding might be tested by the content of Part One, these chapters are a clear demonstration of the importance of understanding such theory, and the rewards of applying the rationale in examining physical examples.

Principles of Roman Architecture is beautifully illustrated throughout, with clear photographs of surviving architecture and an array of plans and measured drawings. Equally valuable are two appendices, the first of which contains a catalogue of measurements and proportions gathered by the author from a variety of Roman structures, whilst the second analyses in detail the dimensions of fifty selected examples of the Corinthian order. This wealth of information will be of interest and practical use to architectural historians, mathematicians and practicing architects alike. The scope of the book is remarkable but Wilson Jones's analysis of Roman construction is restricted to monumental commissions, which made use of cut stone and the classical language. Sadly, although understandably within the context of the book, other less prestigious constructions and building types are overlooked. It would for example be interesting to know whether the mathematical formulae and proportional rules elucidated by Wilson Jones are also apparent in more modest domestic constructions.

Mark Wilson Jones is a practicing architect as well as an architectural historian, a fact which explains both the principal strength and the arithmetic bias of this work. His clinical and dispassionate examination of Roman architecture avoids both the overly florid prose and the dependence on interpretation over evidence, which can weaken an art historical study. A great deal of complex mathematical and geometric information is presented to the reader in the course of the text and thus it is ideally suited to those readers with an enhanced understanding of this field. 
The conclusion drawn by the author, that Roman architects understood certain basic shared principles within their constructions, but that these principles were necessarily stretched or adapted to meet the demands of an individual commission, is convincing. It is also amply supported by the copious evidence presented in the development of this argument. The breadth of the text, and the number of buildings studied, reveal the extensive scope of classical architecture available for study. For architectural historians, who may know much concerning the appearance of classical structures, and yet little about their physical construction, this work provides valuable insight into the practical mechanics of designing and erecting a Roman building.

\section{About the reviewer}

Sarah Clough Edwards received her Ph.D. in Architectural History from the University of Reading. She remains associated with this University where she lectures on Italian architecture of the Renaissance and Baroque period. Her Ph.D. studied the design of the convent of S. Chiara in Urbino and its architect Francesco di Giorgio Martini of Siena. Several articles drawn from this research are now in the process of being published. Her current research is concerned with the architectural evolution of the staircase in the Renaissance period and its symbolic utilization within the complex social mechanisms of the Italian courts. Edwards has also presented a number of conference papers on her research, most recently at the Association of Art Historians annual conference (Bristol, 2005). 